\title{
Tonotopic Gradients of Membrane and Synaptic Properties for Neurons of the Chicken Nucleus Magnocellularis
}

\author{
Iwao Fukui and Harunori Ohmori \\ Department of Physiology, Faculty of Medicine, Kyoto University, Kyoto 606-8501, Japan
}

\begin{abstract}
Nucleus magnocellularis (NM) is a division of the avian cochlear nucleus that extracts the timing of auditory signals. We compared the membrane excitability and synaptic transmission along the tonotopic axis of NM. Neurons expressed a Kv1.1 potassium channel mRNA and protein predominantly in the high characteristic frequency (CF) region of NM. In contrast, the expression of Kv1.2 mRNA did not change tonotopically. Neurons also showed tonotopic gradients in resting potential, spike threshold, amplitude, and membrane rectification. All neurons were sensitive to $100 \mathrm{n}$ м dendrotoxin, but the effects were most significant in the high CF neurons. The EPSC recorded by minimal stimulation of auditory nerve fibers (ANFs) was 13 times larger in high CF neurons than in low CF neurons. Moreover, EPSCs were generated in an all-or-none manner in the high CF neurons when stimulus intensity was increased, whereas EPSCs were graded in the low CF neurons, indicating multiple axonal inputs. ANF synaptic terminals were visualized by DiI. ANF formed enfolding end-bulbs of Held around the cell body in the high and middle CF region but not in the low CF region. These observations indicate coordinated gradients of neuronal properties both presynaptically and postsynaptically along the tonotopic axis. Such specializations may be suitable for extracting and preserving the timing information of auditory signals over a wide range of acoustic frequencies.
\end{abstract}

Key words: potassium channels; cochlear nucleus; synapse; membrane excitability; tonotopy; auditory

\section{Introduction}

Characteristic features of sound are extracted by the nervous system, including frequency, intensity, and interaural timing. Sound frequency is analyzed in the cochlea, and each auditory nerve fiber (ANF) innervating a specific region of the cochlea is associated with a specific characteristic frequency (CF). Sound intensity and timing are encoded as a sequence of spikes in each ANF. The nucleus angularis (NA) and the nucleus magnocellularis (NM) are two divisions of avian cochlear nucleus. The intensity of sound is extracted and coded as a frequency of spikes in the NA, whereas the temporal nature of sound is preserved in the NM (Sullivan and Konishi, 1984; Takahashi et al., 1984; Takahashi and Konishi, 1988a,b; Warchol and Dallos, 1990). Temporal information is then transmitted to the nucleus laminaris (NL), where the interaural timing differences are first computed (Young and Rubel, 1983; Carr and Konishi, 1990; Overholt et al., 1992). These two parallel pathways converge in the inferior colliculus (Knudsen and Konishi, 1978; Brainard et al., 1992) as cues to determine the location of a sound source.

In the cochlea, individual hair cells are tuned to a narrow frequency. Gradient of membrane excitability along the tonotopic axis is reported in hair cells of several species, including

Received Feb. 18, 2004; revised July 14, 2004; accepted July 16, 2004.

This study was supported by the Ministry of Education Grant-in-Aid 12053233 to H.O. and by grants-in-aid from the Narishige Neuroscience Research Foundation to I.F. We appreciate Dr. L. 0. Trussell for careful reading of this manuscript and for valuable comments. We thank Dr. T. M. Ishii for the advice and instruction of molecular biology and Dr. N. Tamamaki for technical advice on in situ hybridization. We appreciate M. Fukao for technical assistance.

Correspondence should be addressed to H. Ohmori at the above address. E-mail: ohmori@nbiol.med. kyoto-u.ac.jp.

DOI:10.1523/JNEUROSCI.0566-04.2004

Copyright $\odot 2004$ Society for Neuroscience $\quad$ 0270-6474/04/247514-10\$15.00/0 birds (Wu et al., 1995; Ramanathan et al., 1999, 2000; Pantelias et al., 2001). In the cochlear nucleus of chicken, Rubel and Parks (1975) demonstrated the tonotopic arrangement in both the NM and NL; NM neurons with lower CF are located in the caudolateral region and those with higher $\mathrm{CF}$ in the rostromedial region. The firing properties of NM neurons are determined primarily by the presence of low-voltage threshold dendrotoxin (DTX)sensitive $\mathrm{K}^{+}$currents (Rathouz and Trussell, 1998), which are probably generated by $\mathrm{K}^{+}$channels Kv1.1, Kv1.2, or Kv1.6 (Hopkins et al., 1994; Harvey, 2001). These serve to shorten the membrane time constant and minimize temporal distortion of signals. Large EPSCs are reported in NM neurons, which reduce the temporal jitter for spike generation to $20 \mu \mathrm{sec}$ (Brenowitz and Trussell, 2001). In rat, immunolabeling to Kv1.1 showed a gradient across the tonotopic axis in the lateral superior olive (LSO), which underlies the firing properties of principal neuron (Barnes-Davies et al., 2004). However, tonotopic gradient of Kv1.1 protein was not clearly demonstrated in the NM of the chicken (Lu et al., 2004).

ANF terminals in NM neurons form large end-bulbs of Held (Parks and Rubel, 1978; Whitehead and Morest, 1981; Jhaveri and Morest, 1982a,b,c), and each neuron receives only one to four such inputs (Hackett et al., 1982; Carr and Boudreau, 1991). However, in the barn owl, ANFs are reported to form bouton-like terminals in the low CF (lower than $0.64 \mathrm{kHz}$ ) region (Köppl, 1994). This may indicate a possible gradient of synaptic properties along the tonotopic axis within the NM. We report here the gradient of expressions of Kv1.1 mRNA and protein, the membrane excitability, synaptic transmission, and terminal morphology of ANF along the tonotopic axis in the chicken NM. 


\section{Materials and Methods}

Slice preparations and electrophysiological recordings. Chickens were deeply anesthetized with halothane before decapitation in all experiments. These procedures conformed to the guiding principles for the care and use of animals in the field of physiological sciences set by the Japanese Physiological Society. Transverse slices of the brainstem (250 $\mu \mathrm{m}$ ) were prepared from postnatal day 2 (P2) to P6 chickens by a tissue slicer, and the detailed procedures have been described previously (Fukui and Ohmori, 2003).

The recording chamber on the stage of an upright microscope (BX50WI; Olympus, Tokyo, Japan) was perfused continuously with artificial CSF (ACSF) at the rate of $2-4 \mathrm{ml} / \mathrm{min}$ by a peristaltic pump (P-3; Amersham Biosciences, Arlington Heights, IL). The temperature of bathing medium filling the recording chamber was maintained during the experiment at approximately the body temperature of chicken (40$41^{\circ} \mathrm{C}$; see Fukui and Ohmori, 2003, for details). Neurons in the NM were visualized by using a $60 \times$ objective with Nomarski optics equipped with an infrared CCD camera (C5999; Hamamatsu, Hamamatsu, Japan).

The whole-cell recording pipette solution contained the following (in $\mathrm{mm}$ ): $130 \mathrm{~K}$-gluconate, $10 \mathrm{HEPES}, 0.2 \mathrm{EGTA}, 10 \mathrm{KCl}, 5 \mathrm{NaCl}$, and 1 $\mathrm{MgCl}_{2}$, adjusted to $\mathrm{pH} 7.2$. The electrode resistance was $2-5 \mathrm{M} \Omega$ in the bath and was $6-15 \mathrm{M} \Omega$ during recording. Current-clamp recording was made by using the Axopatch 200B amplifier (Axon Instruments, Union City, CA) in the fast mode. Data were filtered at $5 \mathrm{kHz}$ with four-pole low-pass Bessel characteristics and were sampled at 20-100 kHz. Liquid junction potential $(10 \mathrm{mV})$ was corrected. Dendrotoxin-I (Alomone Labs, Jerusalem, Israel) or 6-cyano-7-nitroquinoxaline-2, 3-dione (CNQX; Tocris Cookson, Ballwin, MO) was added to ACSF in some experiments.

Neurons were not included in the statistics unless the resting potential was more negative than $-50 \mathrm{mV}$. The following basic parameters were measured as described: membrane resistance, from the slope of $I-V$ relationship by applying small hyperpolarizing current injections; membrane time constant, by injecting hyperpolarizing currents between -0.05 and $-0.1 \mathrm{nA}$; spike threshold potential, the voltage at which the rapid upstroke of action potential began; threshold current, by stepwise current injections of $0.05-0.1 \mathrm{nA}$ increments; spike amplitude, the peak voltage of action potential from the spike threshold when spikes were induced by current injection or from the resting potential when generated by ANF stimulation; spike half-width, the spike duration measured at the spike half-amplitude; temporal jitter of spikes after the ANF stimulus, the SD of time between the stimulus artifact and the spike peak.

In the recording of EPSCs or miniature EPSCs (mEPSCs), $\mathrm{a} \mathrm{Cs}^{+}{ }_{-}$ based internal solution (in mM: $160 \mathrm{CsCl}, 10$ HEPES, 5 EGTA, pH 7.2) was used. To block $\mathrm{Na}^{+}$currents, $5 \mathrm{~mm} \mathrm{~N}$-(2,6-dimethylphenylcarbamoylmethyl) triethylammonium bromide (Alomone Labs) was added to the pipette solution. A large EPSC (larger than $20 \mathrm{nA}$ ) was recorded by reducing the gain of head stage amplifier $(\beta=0.1 ; 50 \mathrm{M} \Omega$ feedback resistor). Ninety to $95 \%$ of series resistance was compensated. The current-voltage relationship of EPSC amplitudes was measured at holding potentials ranging from -40 to $+20 \mathrm{mV}$. The size of current was $13.0 \pm$ $2.4 \mathrm{nA}(n=21)$ at $-40 \mathrm{mV}$, and the relationship was linear $(r=0.995)$, indicating minimum series resistance error. In the recording of EPSPs, EPSCs, and mEPSCs, $20 \mu \mathrm{M}$ strychnine (Sigma, St. Louis, MO), $40 \mu \mathrm{M}$ bicuculline (Sigma) and $50 \mu \mathrm{M}$ D-2-amino-5-phosphonovalerate (APV; Tocris Cookson) was added to the bath medium to block glycinergic and GABAergic inputs and to block NMDA receptor mediated inputs, respectively.

ANF was stimulated by either a glass electrode or a bipolar tungsten electrode. The electrode was placed in the dorsolateral region of NM neurons (at a distance of $\sim 50-150 \mu \mathrm{m}$ from the recorded cell), and electrical stimuli were applied: $50 \mu \mathrm{sec}$ duration of up to $100 \mathrm{~V}$ with the glass electrode or up to $40 \mathrm{~V}$ with the bipolar tungsten electrode. EPSCs were recorded at $-30 \mathrm{mV}$ and $\mathrm{mEPSCs}$ at $-60 \mathrm{mV}$. Data were presented as mean $\pm \operatorname{SE}$ ( $n$, number of cells). Statistical evaluations $(p)$ were made by Welch's unpaired $t$ test or Student's paired $t$ test.

Cloning of chicken Kv1.1, Kv1.2, and Kv1.6 and probes for in situ hybridization. Degenerate primers for the sequence of Kv1.1, Kv1.2, and Kv1.6 having the EcoRI site were designed from mammalian homology: forward, 5' -GCGAATTCATHHTNCCNTAYTTYATHAC-3'; and reverse, 5'-GCGAATTCCATNGTNACNACNGCCCACCA-3'. The longer cDNA clone was obtained by the hybridization of the ${ }^{32} \mathrm{P}$-labeled PCR products with a chicken cDNA library. Sequences of the probe for Kv1.1 (302 bp), Kv1.2 (323 bp), and Kv1.6 (368 bp), containing from $\mathrm{Kv} \beta 1$ interaction domain to S2 domain, were constructed by PCR using the following primer pairs and subcloned in pBluescript (Stratagene, La Jolla, CA): Kv1-forward, 5'-AHSTTYCGKGARGAYGAAGG-3'; and Kv1-reverse, 5'-CAGATRATGCAMAGBGTCTC-3'. Digoxigenin (Dig)-labeled RNA probes were synthesized by in vitro transcription using the Dig RNA labeling kit (Roche Products, Hertfordshire, UK) following the protocol of the manufacturer.

In the Kv1.1 and Kv1.2 in situ hybridization, the use of the other probes detecting other regions of Kvl.1 and Kv1.2 constructed by PCR of the following primer pairs [containing ORF-end and 3'UTR (untranslated region)] showed the same results (data not shown): Kv1.1-reverse, 5'-GAAGCTTCTTTATCGCTGAGC-3' and Kv1.1-forward, 5' -ATGTTAGCTCCCCAAATTTAGC-3' (353 bp); Kv1.2-reverse, 5' -ACTTACACAGCTATTGCTTCCC-3' and Kv1.2-forward, 5' -CTCAGTATTTGCAAGTAACCAGC-3' (354 bp).

In situ hybridization. Four posthatched chickens (P3, P7, P10, and P15) were used. Brain slices $(20 \mu \mathrm{m})$ were fixed for $5 \mathrm{~min}$ in $0.1 \mathrm{M}$ phosphate buffer, $\mathrm{pH} 7.4$, containing $4 \%$ paraformaldehyde and washed two times each for $5 \mathrm{~min}$ with $0.1 \mathrm{M}$ phosphate buffer. After incubation for $5-10 \mathrm{~min}$ at $37^{\circ} \mathrm{C}$ with $10 \mu \mathrm{g} / \mathrm{ml}$ proteinase $\mathrm{K}$ (Roche Products) in 0.1 M Tris, $\mathrm{pH} 8.0$, and $0.05 \mathrm{~m}$ EDTA, they were acetylated for $10 \mathrm{~min}$ with $0.25 \%$ acetic anhydride in $0.1 \mathrm{M}$ triethanolamine and washed two times each for 5 min with $2 \times$ SSC at room temperature. This was followed by prehybridization for $2 \mathrm{hr}$ at room temperature in $50 \%$ deionized formamide, $5 \times$ SSC, $5 \times$ Denhardt's solution (Wako, Tokyo, Japan), 250 $\mu \mathrm{g} / \mathrm{ml}$ yeast tRNA (Roche Products), and $500 \mu \mathrm{g} / \mathrm{ml}$ salmon sperm DNA (Invitrogen, San Diego, CA). Hybridization was conducted at $55^{\circ} \mathrm{C}$ overnight with the denatured Dig-labeled probes in the prehybridization solution $(1.25 \mu \mathrm{g} / \mathrm{ml})$. The sections were then washed three times each for 20 min with $4 \times$ SSC, and nondigested probes were degraded by a 30 min incubation at $37^{\circ} \mathrm{C}$ in RNase solution containing $20 \mu \mathrm{g} / \mathrm{ml}$ RNase A (Sigma), $0.5 \mathrm{~m} \mathrm{NaCl}, 0.01 \mathrm{~m}$ Tris, $\mathrm{pH} 8.0$, and $1 \mathrm{~mm}$ EDTA. They were then washed with SSC solution with $1 \mathrm{~mm}$ dithiothreitol $(2 \times$ SSC for 5 min two times, $1 \times$ SSC for $5 \mathrm{~min}, 0.5 \times$ SSC for $5 \mathrm{~min}, 0.1 \times$ SSC for 30 $\mathrm{min}$ at $65^{\circ} \mathrm{C}, 0.1 \times \mathrm{SSC}$ for $5 \mathrm{~min}$ ). Sections were immunoblotted with 1/2000-diluted anti-Dig-antibodies conjugated with alkaline phosphatase (Roche Products) at $4^{\circ} \mathrm{C}$ overnight. The bound alkaline phosphatase was visualized by NBT (nitro blue tetrazolium chloride)/BCIP (5bromo-4-chloro-3-indolyl phosphate salt) stock solution (Roche Products). Sense-RNA was used as a control. We could not detect any significant signals using these control probes.

Immunohistochemistry. Antibodies for C terminal of mouse Kv1.1 protein were obtained from Alomone Labs (APC-009). The staining pattern by this antibody was similar to that in the study by Lu et al. (2004). Four posthatched chickens (P3, P8, P10, and P11) were perfused through the heart with $10 \%$ formalin-PBS, and brains were dissected out, postfixed for $2 \mathrm{hr}$ in 10\% formalin-PBS, and kept overnight in 30\% sucrose-PBS. Sagittal sections $(20-30 \mu \mathrm{m})$ were cut and collected in PBS. Endogenous peroxidase was quenched by incubating sections for $10 \mathrm{~min}$ in $0.3 \%$ hydrogen peroxide-PBS. Sections were washed with PBS, incubated for 1 hr in an incubation buffer containing 1\% BSA, 0.25\% carrageenan (Sigma), $0.02 \%$ sodium azide, $0.3 \%$ Triton X-100 in PBS, incubated overnight at $4^{\circ} \mathrm{C}$ with antibody $(1: 200)$, washed with $0.3 \%$ Triton X-PBS, and then incubated in a 1:500 dilution of biotin-conjugated donkey antirabbit IgG (Chemicon, Temecula, CA) in the incubation buffer. After washing with $0.3 \%$ Triton X-PBS, slices were incubated in avidinhorseradish peroxidase $\mathrm{ABC}$ solution (Vector Laboratories, Burlingame, $\mathrm{CA}$ ) for $2 \mathrm{hr}$, reacted with a 3, 3' -diaminobenzidine (DAB; Wako) solution containing $0.2 \% \mathrm{DAB}, 0.02 \% \mathrm{NiCl}_{2}, 0.001 \% \mathrm{H}_{2} \mathrm{O}_{2}$, and $50 \mathrm{~mm}$ Tris, $\mathrm{pH} 7.4$

DiI labeling. The projection of ANFs was examined in both live and fixed preparations (total of 31 chickens; P2-P9). In live preparations, crystals of DiI were placed in the cochlea. The cochlear organ was ap- 


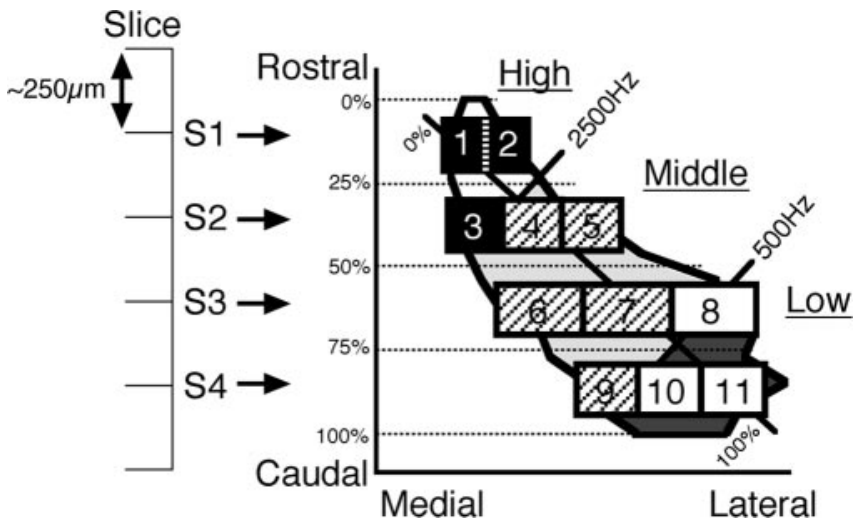

Figure 1. Schematic representation of the tonotopic organization of NM. The mediolateral extension of NM was measured from the rostral plane to the caudal plane of slices. The region is indicated as a percentage of rostrocaudal and mediolateral extensions. The schema shows the average outline of NM reconstructed from two chickens ( $\mathrm{P3}, \mathrm{P} 5)$. By applying linear regression, the tonotopic distribution in NM was represented quantitatively by a linear function against the percentage of the anteroposterior axis or the mediolateral axis (Rubel and Parks, 1975). The $25 \%$ line from the rostromedial edge will correspond to $\mathrm{CF} 2500 \mathrm{~Hz}$, and the $75 \%$ line will correspond to $\mathrm{CF} 500 \mathrm{~Hz}$. When we cut the brain stem from the rostral to the caudal direction at $250 \mu \mathrm{m}$ thickness (left scale), the NM was divided into four sections (S1-S4; arrows). These sections were divided into two or three regions from the medial to lateral as illustrated by the boxes with numbers. Neurons recorded were further grouped into three CFs. Neurons recorded from filled boxes (boxes 1, 2, and 3) were defined as high (F neurons, hatched boxes (boxes 4,5, 6,7 , and 9 ) as middle $(F$ neurons, and open boxes (boxes 8,10 , and 11 ) as low $C F$ neurons.

proached from the oval window after removing the columella and stapedial footplate. After placing DiI, the oval window and part of the middle ear were sealed by Sylgard. After 1-2 d, ANF projection to the NM was observed in slices. In fixed preparations, chickens (P3-P9) were perfused through the heart as described above and were postfixed for 1-10 $\mathrm{hr}$ at $4^{\circ} \mathrm{C}$. DiI crystal was placed in either the NA $(n=1)$ or the cochlea $(n=$ 12 ), and the brain was incubated for 1-2 months in PBS containing $0.02 \%$ sodium azide at $37^{\circ} \mathrm{C}$ and sliced.

\section{Results}

The classification of NM neurons in this study

Rubel and Parks (1975) described the tonotopic layout of NM semiquantitatively as a linear function against the axis of the nucleus: $\mathrm{CF}$ against the percentage of anteroposterior axis or against the mediolateral axis in both NM and NL. Following their protocol, we classified the regions of our slices into high, middle, and low CF regions. When we made transverse slices of the brain stem from the rostral toward the caudal direction at $250 \mu \mathrm{m}$ thickness, four sections were obtained across NM (S1-S4) (Fig. 1 ). The transverse slices were cut oblique to the tonotopic axis and do not match the tonotopic map per se. We therefore took parts of these four sections and classified them into three regions of CF; S1 was divided into the medial and lateral regions (Fig. 1, regions 1 and 2). These two $S 1$ regions, together with the region of the medial one-third of S2 (region 3), were classified as the high CF region (Fig. 1, filled boxes). The lateral two-thirds of S2 (regions 4,5 ), the medial two-thirds of S3 (regions 6,7 ), and the medial one-third of S4 (region 9) were classified as the middle CF region (Fig. 1, hatched boxes). The lateral one-third of S3 (region 8 ) and the lateral two-thirds of S4 (regions 10, 11) were considered as the low CF region (Fig. 1, open boxes). The level of the four sections could be confirmed by the arrangement of nearby NL neurons included within each slice (Fig. 2). In S1, NL neurons had a ventromedial to dorsolateral orientation (Fig. $2 A a, B a$ ). NL neurons were lined up from the mediolateral orientation in S2 (Fig. 2Ab). In S3, NL neurons were scattered or formed several
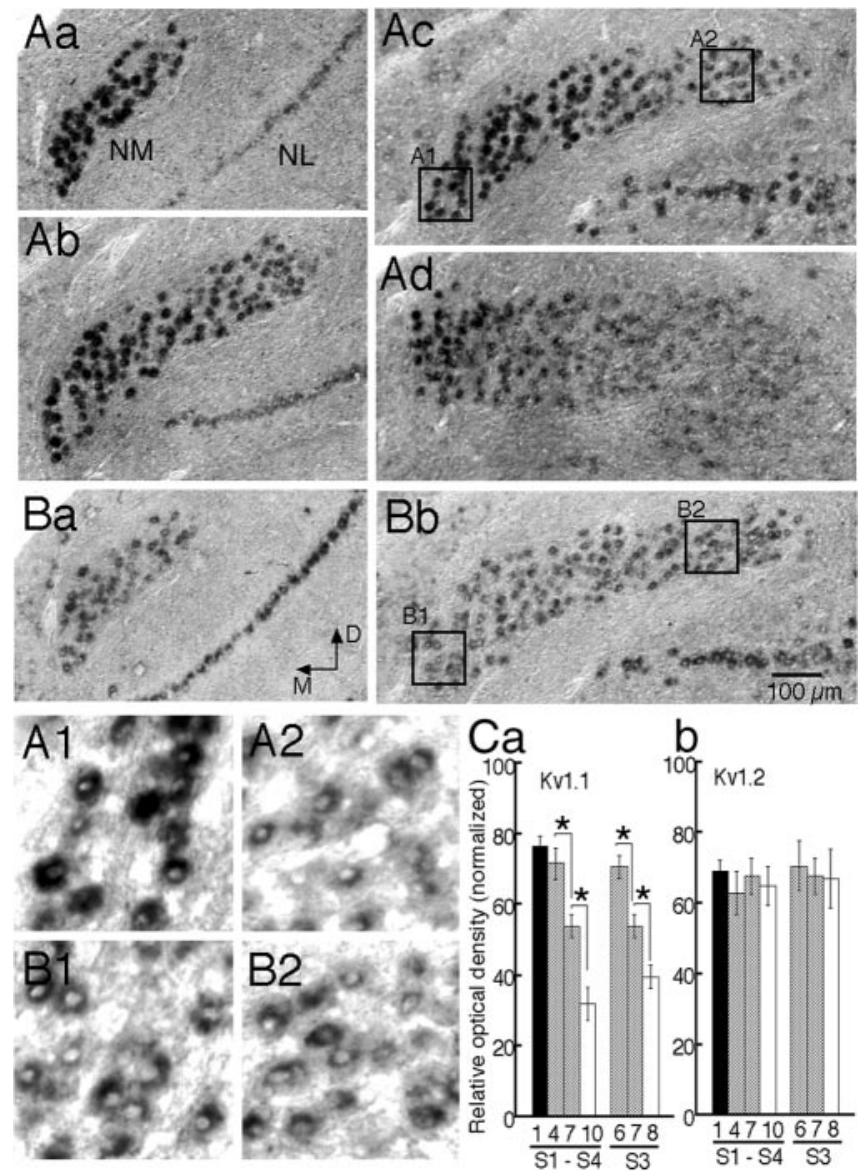

Figure 2. Expression of Kv1.1 and Kv1.2 mRNA. $A, B$, Expression patterns of Kv1.1 mRNA ( $A)$ and Kv1.2 mRNA ( $B)$ detected by in situ hybridization. $A a$ and $B a, \mathrm{~S} 1 ; A b, S 2 ; A c$ and $B b, S 3 ; A d$, $S 4$ (see Fig. 1). $A 1, A 2, B 1, B 2$, High magnification of boxes in $A c$ and $B b$ (these two boxes correspond to the medial and lateral regions of $\mathrm{S3}$ ). The intensity of Kv1.1 mRNA decreased toward the lateral and caudal regions. The intensity of Kv1.2 mRNA was almost constant throughout the nucleus. C, In this figure and in Figure $3 B$, the optical densities of individual cells were measured and averaged in each region (the number indicated below the abscissa is the region number, as shown in Fig. 1). S1-S4, Numbered regions sampled across sections S1 to S4; $\mathrm{S3}$, regions $6-8$ are from the section $\mathrm{S3}$. Data from four chickens of different ages were averaged and plotted for Kv1.1 (Ca) and for Kv1.2 (Cb). Statistical significance is indicated by an asterisk ( $\left.{ }^{*} p<0.05\right)$. M, Medial; D, dorsal.

lines (Fig. $2 A c, B b$ ). NL neurons were not observed in slice S4 (Fig. $2 A d)$. Slices were not used for the experiments when these classifications were difficult. The border between the high CF region and the middle CF region may be $\sim 2.5 \mathrm{kHz}$ and $\sim 500 \mathrm{~Hz}$ for the border between the middle CF region and the low CF region (Rubel and Parks, 1975). In the following experiments, an almost equal number of neurons was recorded in all three $\mathrm{CF}$ regions and almost equally from each subregion.

\section{Expression of Kv1.1 and Kv1.2}

Figure 2 shows the patterns of expression of Kv1.1 and Kv1.2 mRNAs in NM. In the most rostral section (S1) (Fig. 2Aa), the intensity of Kv1.1 mRNA expression was high, but the intensity declined toward the caudal and lateral regions (Fig. $2 \mathrm{Ab}-$ $d, A 1, A 2)$. Figure $2, A 1$ and $A 2$, shows the area $A 1$ and $A 2$ of Figure $2 A c$ in the expanded magnification. The expression of Kv1.2 mRNA was almost homogeneous throughout NM (Fig. $2 B a, b$, and B1, B2 for expanded magnification). The level of Kv1.6 mRNA was very weak and was not different from the level of negative controls, namely the sense-RNA probes of Kv1.1, Kv1.2, 
and Kv1.6 (data not shown). The optical density of neurons in these in situ hybridization images was calculated by taking the average of pixel intensity corresponding to single neurons (30-70 neurons were counted in each region). These measurements were made from the cell soma including the area of nucleus. In these calculations, the neuron of the highest intensity was rated 100, and the intensity of background area was rated 0 . Other neurons were scaled between 0 and 100 , and the grand average was calculated for regions $1-11$ of Figure 1.

Figure $2 C$ plots the optical density of Kv1.1 averaged from four chickens (P3, P7, P10, and P15) against regions 1, 4, 7, and 10 along the tonotopic axis and against the mediolateral axis for regions 6, 7, and 8 in slice S3 (Fig. 2Ca). In both plots, the intensity was higher in the higher $\mathrm{CF}$ region (columns indicated by filled bars or gray bars) than in the low CF region (open bar column), and the difference was significant (Fig. $2 \mathrm{Ca})\left({ }^{*} p<\right.$ $0.05)$. Kv1.2 did not show these gradients (Fig. 2Cb).

The antibody to the mouse Kv1.1 protein, which recognizes the $\mathrm{C}$ terminal of the protein, cross-reacted with the chicken Kv1.1 protein (Fig. 3). The intensity of NM neurons was rated as described above, and averaged intensity of each region from four chickens (P3, P8, P10, and P11) was plotted in Figure 3B. The expression was most intense in the rostromedial region, and the intensity declined toward the caudolateral region. The intensity showed a significant gradient at all ages, and this tendency was almost in parallel with the pattern of expression of Kv1.1 mRNA in the in situ hybridization (Fig. 2C). The immunoreactivity of Kv1.1 did not show any specific subcellular differences (Fig. $3 A 1, A 2)$. In the NL, the somatic region was negative and only the dorsal and the ventral neuropil regions, probably the dendrites, were Kv1.1 protein positive (Fig. $3 A a$ ). This was in contrast to the somatic expression of Kv1.1 mRNA (Fig. 2A,B). The antibodies for the $\mathrm{C}$ terminal of human and rat Kv1.2 protein (s.c.-11188, Santa Cruz Biotechnology, Santa Cruz, CA, and APC-010, Alomone Labs, respectively) did not show any reaction product.

\section{Membrane excitability along the tonotopic axis}

Membrane excitability was examined in $125 \mathrm{NM}$ neurons: 35 from the high CF region, 45 from the middle CF region, and 45 from the low $\mathrm{CF}$ region. All NM neurons generated action potentials only at the onset of depolarizing current injection and a depolarizing sag during hyperpolarizing responses (Fig. 4). However, as illustrated in Figure 5, there were systematic differences in membrane excitability among these neurons. The resting potential was the most negative in high CF neurons and the least negative in low CF neurons (Fig. 5Aa). The threshold voltage for action potentials was most negative in low CF cells (Fig. 5Aa), which may have facilitated generation of off-response action potentials after hyperpolarizing current injection (Fig. 4C, arrowhead). Eighty-four percent of the low CF neurons ( 38 of 45 cells) and $11 \%$ of middle CF neurons ( 5 of 45 cells), but no high CF neurons, generated off responses. The input resistance of the low CF neurons measured by the current injection of $-0.1 \mathrm{nA}$ was higher than that of the high CF neurons (Fig. 5Ab). The membrane time constant was shorter in the high CF neuron than the low CF neuron (Fig. 5Ac). Because of the lower resting potential, the less negative threshold potential, and the lower membrane resistance, high CF neurons required a larger current to fire than the low CF neurons (Fig. 5Ad). The spike amplitude was smaller in the high CF neurons than the low CF neurons (Figs. 4, 5Ae). Approximately half of the low CF cells (26 of 45 cells; 58\%) generated few action potentials at the beginning of current injection (Fig. $4 C$ ), and some (5 of $45 ; 11 \%$ ) fired repeatedly during the
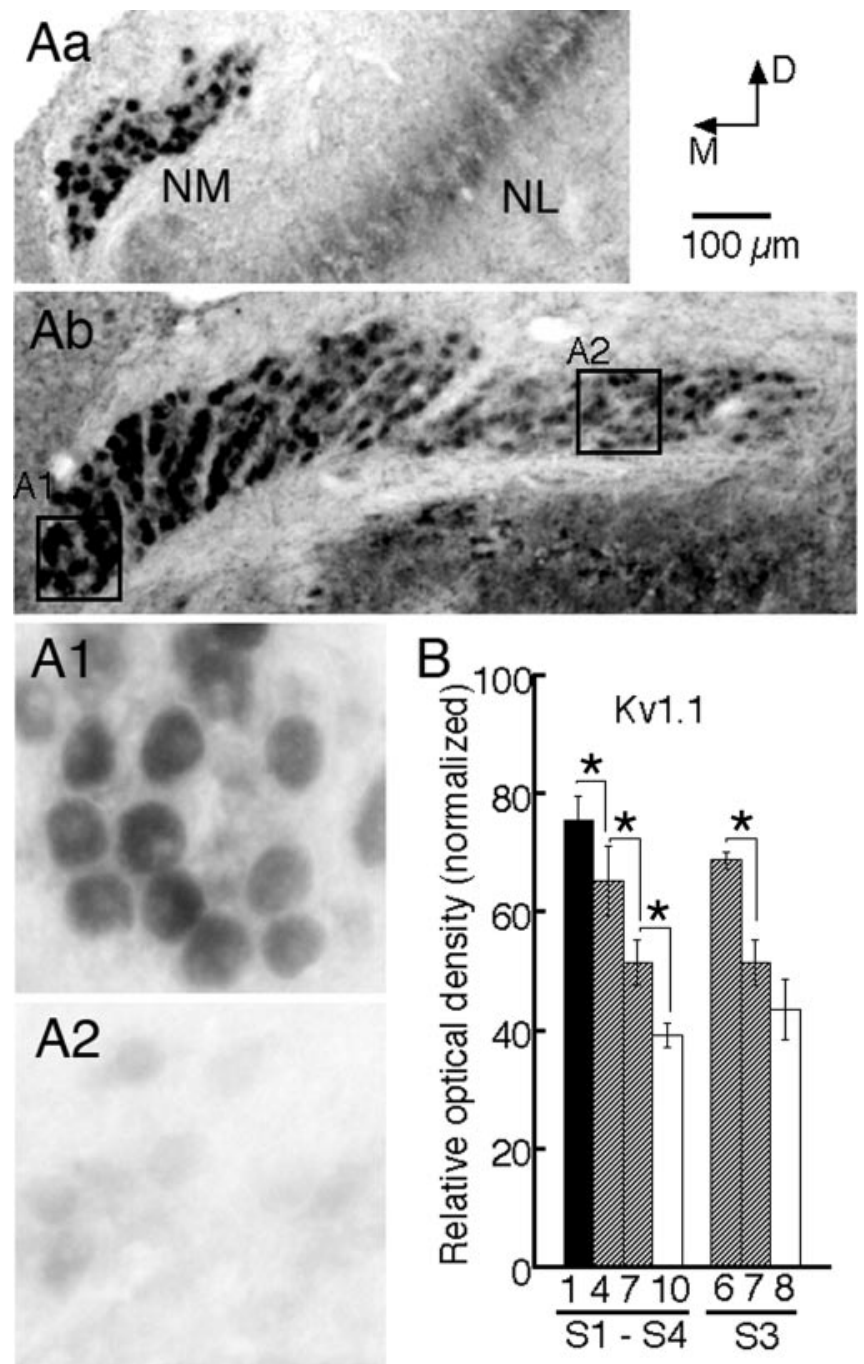

Figure 3. Expression of Kv1.1 protein. $A$, The expression of Kv1.1 protein in NM. $A a, \mathrm{~S} 1 ; A b$, S3. $A 1, A 2$, The high magnification of two boxes in $A b$. The intensity of immunoreactivity was decreased toward the lateral and to the caudal edge of the nucleus, and the tendency was similar to the expression of Kv1.1 mRNA (Fig. 2A). B, The optical densities of individual cells were measured and averaged in each region. Data from four chickens of different ages were averaged and plotted. Statistical significance is indicated by an asterisk ( $\left.{ }^{*} p<0.05\right)$. M, Medial; D, dorsal.

current injection (data not shown). The current-voltage relationship measured at the pulse end $(190 \mathrm{msec})$ was plotted in Figure $5 B$ by filled symbols for the control. The outward rectification was more significant in the high CF neurons than in the low CF neurons. The membrane resistance measured from the limiting slope of $I-V$ relationships $(-0.4$ and $-0.5 \mathrm{nA})$ was almost the same among NM neurons ( $56.4 \pm 4.7 \mathrm{M} \Omega$ for the high CF neurons; $58.6 \pm 3.9 \mathrm{M} \Omega$ for the low CF neurons) (Fig. $5 B$ ). These observations indicate that the low input impedance of the high CF neuron is attributable to the predominance of some voltage-dependent outward currents.

\section{Effects of DTX on the membrane excitability}

All NM neurons were DTX sensitive, but effects were different depending on the $\mathrm{CF}$ region. Figure $5 C$ illustrates an example recorded from the high CF neuron. After DTX (100 nM) application, multiple action potentials were generated at the level of current, which did not induce any action potentials in the control 
$(0.1 \mathrm{nA})$ (Fig. 5Cb). The steady-state current-voltage relationship is plotted in Figure $5 B$. The large differences of the outward rectification observed in the control cases (filled symbols) were no longer observed after DTX application (open symbols), and the current-voltage relationships were almost superimposing in all three CF regions. The effect of DTX was the strongest for the high CF neurons and was the weakest in the low CF neurons, as seen through the threshold potential (Fig. $5 A a$, triangles), resting potential (Fig. $5 A a$, circles), input resistance (Fig. $5 A b$ ), membrane time constant (Fig. 5Ac), threshold current (Fig. 5Ad), and spike amplitude (Fig. 5Ae). Low CF neurons generated spontaneous action potentials in DTX (all 11 cells tested). This could be caused by the decrease of the threshold potential together with the positive shift of the resting potential, because these neurons had a very low threshold (Fig. 5Aa). For these neurons, we could not determine the stable resting potential; therefore, it was estimated as the average of the threshold potential and the negative peak of the afterhyperpolarization. The effect of DTX was similarly observed under the block of synaptic inputs in the presence of $20 \mu \mathrm{M}$ CNQX, $50 \mu \mathrm{M}$ APV, $40 \mu \mathrm{m}$ bicuculline, and $20 \mu \mathrm{M}$ strychnine (data not shown). Many NM neurons started to generate action potentials after DTX at the offset timing of the hyperpolarizing current injection ( 4 of 12 cells in high CF, 8 of 13 cells in middle CF, and all 11 cells in low CF region).

\section{Gradients of EPSCs along the tonotopic axis}

Figure 6A shows EPSCs recorded from NM neurons. The intensity of the stimulus applied to the NM branch of ANF was increased gradually. EPSCs emerged in an all-or-none manner in most of the high CF and the middle CF neurons. However, in some neurons of middle CF (Fig. $6 B b, C b$ ) and most of the low CF neurons (Fig. $6 B c, C c)$, intermediate-sized EPSCs were observed. The inset in Figure 6Ac shows the stepwise increase of the EPSC size in one low CF neuron at higher gain. These small EPSCs are most likely generated by recruiting several ANFs as the increase of electrical stimulus.

The smallest EPSC (sEPSC) (Fig. $6 \mathrm{Ca}-\mathrm{c}$, open circles) recorded in each neuron probably illustrates transmission by a single ANF (an sEPSC is indicated by the arrow in Fig. $6 \mathrm{Ac}$ inset, and the average level of sEPSCs is indicated by the arrows in Fig. $6 B)$. There was a 13 -fold difference in the amplitude of sEPSCs between the high CF and the low CF neurons (Table 1). Despite

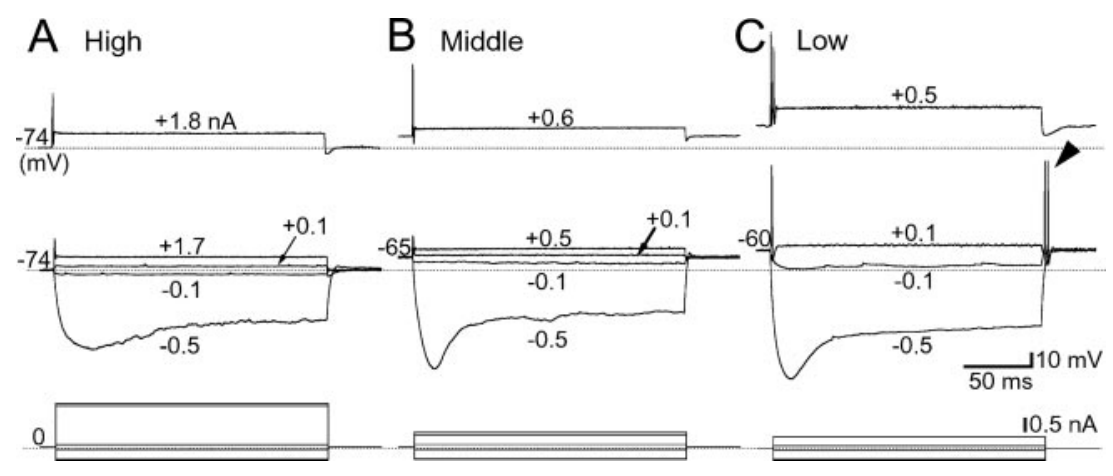

Figure 4. Differences in the firing pattern. Voltage responses to the current injections were illustrated for the high CF neuron $(A)$, middle $C F$ neuron $(B)$, and low CF neuron ( $C$ ). Dashed lines indicate the resting potential of this high CF neuron. The high CF neurons required a larger amount of current injection to be fired than did the low CF neurons. Some low CF neurons showed a few action potentials at the onset of the pulse and at the offset of the hyperpolarized pulse (arrowhead). The bottom traces indicate the injected currents. To facilitate comparison, voltage responses generated by $+0.1 \mathrm{nA}$ current injection are indicated by arrows in $A$ and $B$. Injection of $+0.1 \mathrm{nA}$ current induced the action potential in $C$.
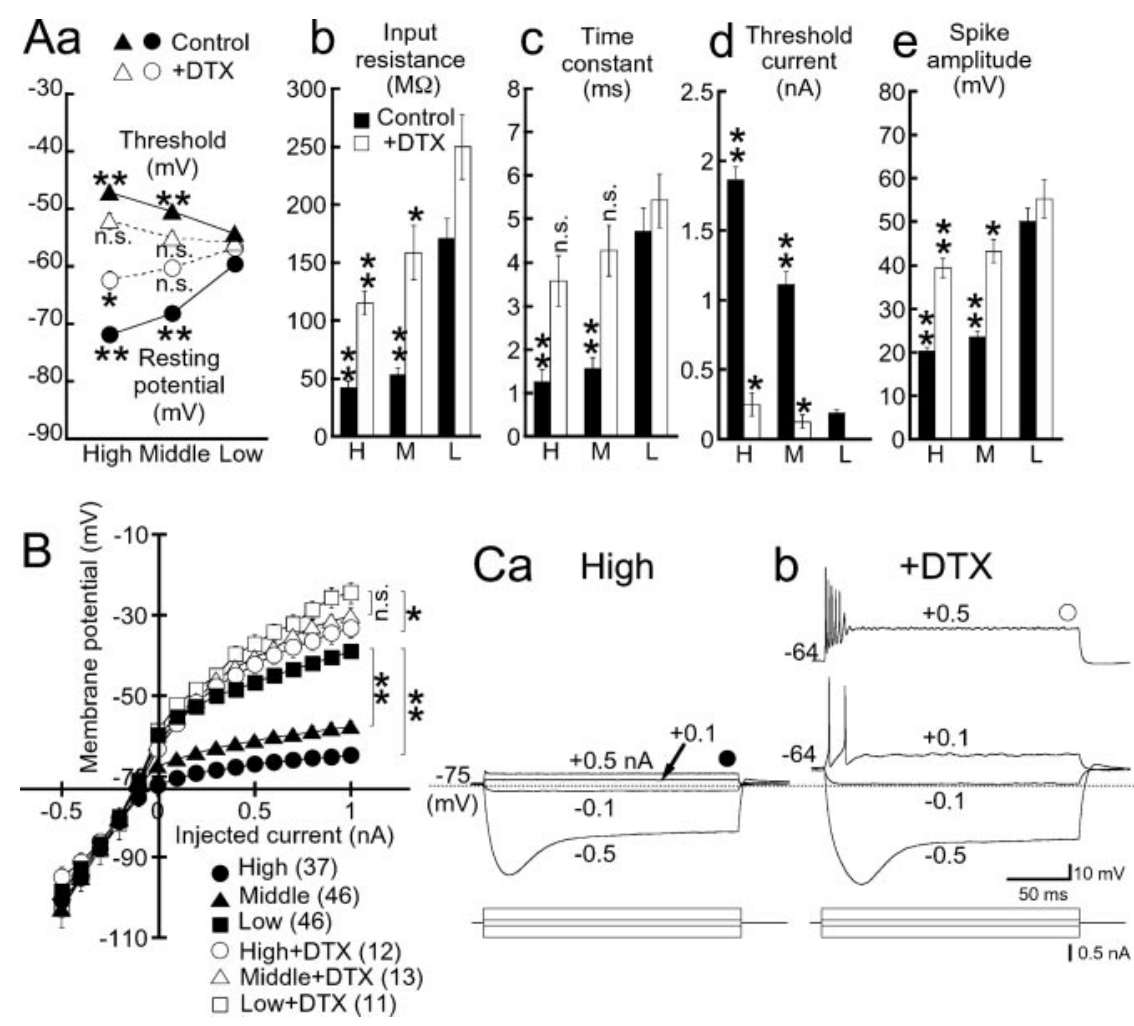

Figure 5. Differences in membrane properties and the effect of $100 \mathrm{~nm}$ DTX. $A$, The membrane property of NM neurons in control (filled symbols) and in the presence of DTX (open symbols). In control, the high (F neurons had more negative resting potential (circles) and less negative threshold potential (triangles; $a$ ), lower input resistance $(b)$ and membrane time constant ( $c$ ), higher threshold current $(d)$, and smaller spike amplitude $(e)$. In the presence of $100 \mathrm{~nm}$ DTX, the resting potential of all neurons became less negative, and the threshold potential became more negative. DTX increased the input resistance, time constant, and spike amplitude and decreased the threshold current. Note that the effects of DTX were relatively small in low CF neurons and the largest in high (F neurons. B, Current-voltage relationships measured at the pulse end (190 msec) in control (closed symbols) and in the presence of DTX (open symbols) for high (F neurons (circles), middle (F neurons (triangles), and low (F neurons (squares). High and middle CF neurons showed a strong outward rectification in the control, which mostly disappeared in DTX. In the presence of DTX, there was no significant difference in the current-voltage relationships among NM neurons. C, Voltage responses of a high CF neuron in control $(a)$ and in the presence of DTX $(b)$. DTX shifted the resting potential from -75 to $-64 \mathrm{mV}$ and reduced the threshold current, and neurons showed multiple action potentials in the presence of DTX. Statistical significance against low (F neurons is indicated by asterisks $\left({ }^{*} p<0.05\right.$; ${ }^{* *} p<0.01$ ) or n.s. (not significant; $p>0.05$ ).

this large difference of sEPSC amplitude, the kinetics of sEPSCs (the rise time and the half-width) was not significantly different.

By the increase of stimulus intensity, the amplitude of EPSCs was increased threefold in the low $\mathrm{CF}$ neuron (Fig. $6 \mathrm{Cc}$, hatched 

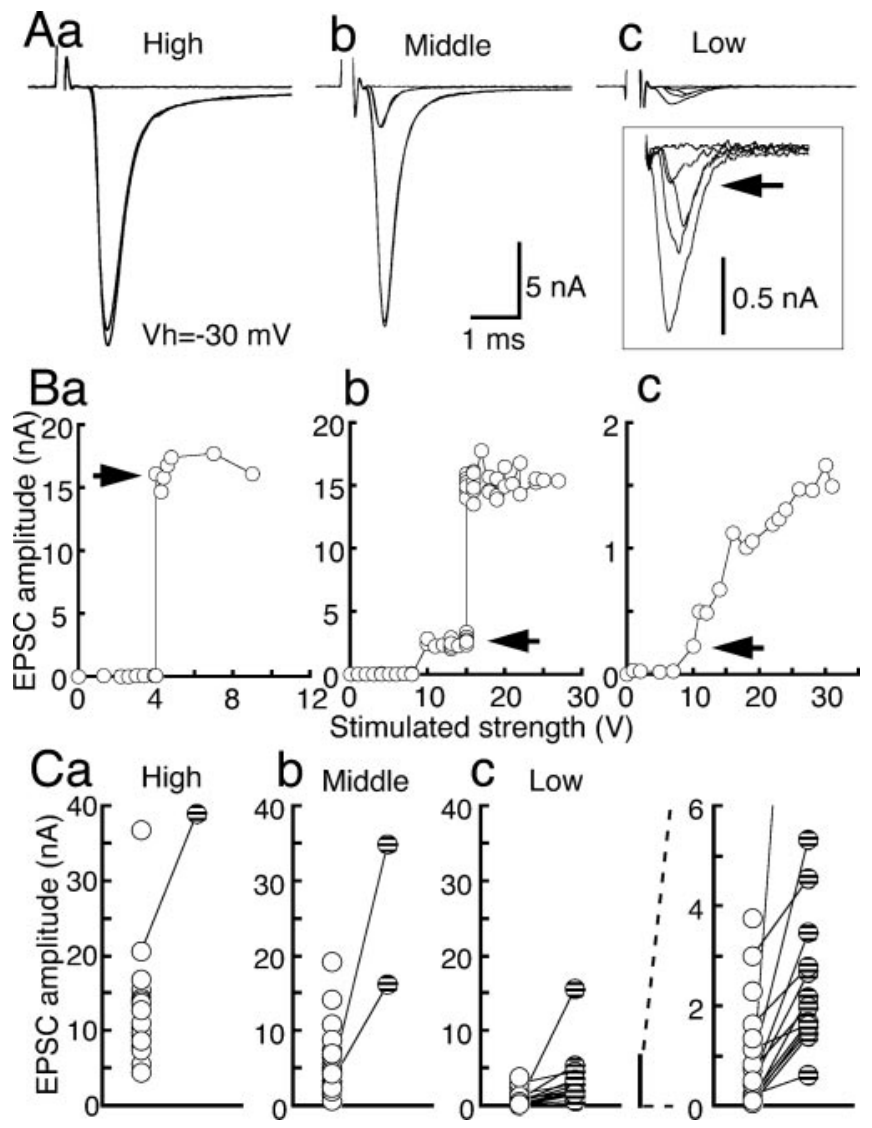

Figure 6. EPSCs in three CF neurons. $A$, EPSCs were recorded at $-30 \mathrm{mV}$ in three CF NM neurons by a series of increased stimulus intensities. $A c$, Inset, Higher gain traces of the current in $A c$. The arrow indicates the smallest EPSC. Most of the high CF $(A a)$ and the middle CF neurons showed an all-or-none response, and a substep was observed in some neurons ( $A b)$. Low CF neurons showed many substeps $(A C)$. $B$, The amplitude of EPSC against the stimulus intensity ( $B a, B b$, and $B C$ are from $A a, A b$, and $A c$, respectively). Arrows show the level of the sEPSC observed in each neuron. $(a-C c$, Size of the sEPSC (open circles) and the maximum EPSC (hatched circles) was connected by a solid line for each neuron: $a$, high (F neurons; $b$, middle CF neurons; $c$, low CF neurons.

circles), whereas the amplitude increased only rarely in the high and in the middle CF neurons (Fig. 6Ca,b, open and hatched circles connected). In case a larger EPSC was generated in the high and middle CF neurons, they were almost within the range observed in sEPSCs (one exception is shown in Fig. 6Cb). The rise and decay kinetics of the largest EPSC were not significantly different from those of the sEPSC.

Despite a large difference in the EPSC amplitude among different CF neurons, the amplitude of mEPSCs was not different (Table 1). The kinetics of mEPSCs was not different either; the rise time, half-width, and decay time constant (in both the absence and presence of TTX; $1 \mu \mathrm{M}$ ). These observations, that the size of the EPSC was systematically different among different CF regions, whereas the size and the kinetics of mEPSCs were not different, indicate that the number of released transmitter vesicles per EPSC was different systematically.

\section{Orthodromic action potentials and the jitter of firings}

Orthodromic spikes were elicited by the stimulation of auditory nerve fibers. Action potentials observed in the high CF $(n=13)$ and the middle CF $(n=9)$ neurons were generated in an all-ornone manner and were not preceded with depolarization attrib- utable to EPSP even at the lower stimulus intensity. However, $60 \%$ of the low CF neurons ( 6 of 10 cells) generated only the EPSP without spikes at low stimulus intensities. The size of EPSP was increased stepwise with the increase in stimulus intensity and finally generated an action potential (Fig. $7 A$, thin traces). At the highest level of stimulus, an antidromic spike was occasionally generated. Antidromic spikes were typically generated without delay from the stimulus artifact (Fig. $7 A$, thick trace); the second peak after the antidromic spike may be the EPSP superimposed on the falling phase of the spike.

Figure $7 B$ shows orthodromic spikes in the high $C F$ and the low CF neurons in expanded time scale. The stimulus applied to the ANF in low CF neuron was the maximal intensity possible without generating antidromic spikes. The spike amplitude was larger in the high CF neurons $(54.3 \pm 10.8 \mathrm{mV} ; n=13)$ than those generated by current injections $(20.3 \mathrm{mV})$. Spike amplitude of the middle CF neurons was similarly large $(47.6 \pm 14.7 \mathrm{mV}$; $n=9)$. However, in the low CF neurons, the spike amplitude $(55.1 \pm 13.7 \mathrm{mV} ; n=16)$ was not different from those recorded by current injections $(50.5 \mathrm{mV})$. All spikes were fast, and the half-width was $\sim 0.4 \mathrm{msec}$.

When tetanic stimulation was applied to ANF, all neurons generated action potentials at least following the frequency tested, up to $333 \mathrm{~Hz}$. Therefore, the capability of firing may not be different fundamentally in these three CF classes of neurons. Action potentials were followed by afterdepolarization in the high CF neurons but afterhyperpolarization in the low CF neurons (94\%) and in the half of the middle CF neurons (44\%). The afterhyperpolarization disappeared by membrane hyperpolarization (toward $-70 \mathrm{mV}$ ) by passing current, indicating an increase in $\mathrm{K}^{+}$conductance. The depolarizing afterpotential was caused by the activation of AMPA and NMDA receptors (Zhang and Trussell, 1994).

Figure $7 B$ also shows a different extent of temporal jitter by superimposed traces of orthodromic spikes between the high CF (20 traces) and the low CF (16 traces) neurons. The time indicating the earliest and the most delayed spike peak is shown by bars. The temporal jitter defined as the SD of spike time (see Materials and Methods) was $9 \mu \mathrm{sec}$ for this high CF neuron and $21 \mu \mathrm{sec}$ for this low CF neuron. Temporal jitter was not significantly different among three groups of NM neurons (Fig. 7C). Application of DTX (100 nM) did not affect the temporal jitter in two high and three middle CF neurons; $12.3 \pm 1.1 \mu \mathrm{sec}$ in the control, and $14.4 \pm 3.1 \mu \mathrm{sec}(n=5)$ in DTX $(p=0.37)$. This is because of the large EPSC (Fig. 6). In the low CF neuron, because of spontaneous firing, temporal jitter was not evaluated in DTX.

\section{The different morphology of synaptic terminals in NM}

Terminal morphologies of ANF were observed by placing DiI in the cochlear organ either in the live chicken or after fixation or in the NA after fixation (total of 31 chickens). Figure $8 \mathrm{~A}$ shows the slice at the level of S3, and the slice shows many ANFs innervating the NM in the dorsolateral direction. Many ANFs innervating the medial region of S3 showed circular structures. Three regions corresponding to boxes $c-e$ in Figure $8 A$ are illustrated in the larger magnification in Figure $8 C-E$. High CF neurons (Fig. $8 B$, reconstructed from slice $\mathrm{S} 1$ ) and middle $\mathrm{CF}$ neurons (Fig. $8 C$ ) were covered with large ANF terminal structures. These terminations may correspond with the end-bulb of Held (Jhaveri and Morest, 1982a,b,c). In the intermediate region between middle and low CF (Fig. 8D), ANF endings that looked like clustered bouton terminals were observed. Large ANF endings were not 
observed in the low CF region (Fig. $8 E$ ) in any of the chickens examined. Gradients of terminal structure were observed similarly in preparations either DiI was placed in the live cochlea or after fixation. Large enfolding ANF terminals were found in $86.4 \%$ of high CF neurons ( 83 of 96 cells in $\mathrm{S} 1$; reconstructed from four chickens, $\mathrm{P} 5-$ P9) and $87.6 \%$ of the middle CF neurons (107 of 124 cells in region 6 in S3). These percentages should be underestimated, because not all ANFs were reconstructed. In these calculations, ANF terminals covering $>25 \%$ of the cell circumference in confocal slices were counted positive. In the middle to low $\mathrm{CF}$ region (region 7 in S3), $40 \%$ of neurons ( 46 of 114 cells) were covered with the large terminals. In the lateral region (region 8 in S3), no enfolding terminals were found ( 0 of 101 cells); instead, many bouton-like terminal structures were observed. The diameter of ANFs also showed tonotopic gradients (Fig. $8 F$ ). ANFs of low $\mathrm{CF}$ region were thinner than that of middle or high CF region. The mean diameter was from 1.93 to $2.13 \mu \mathrm{m}$ for the high to middle CF region and was from 1.13 to $1.36 \mu \mathrm{m}$ for the low CF region. These differences of axonal diameter were statistically significant (Fig. $8 F)(p<0.01)$.

\section{Discussion}

We have demonstrated that membrane excitability and synaptic properties differed systematically along the tonotopic axis of the NM. The gradient of membrane excitability was determined primarily by the amount of DTX-sensitive low-threshold $\mathrm{K}^{+}$current (Fig. 5). Synaptic transmission also showed a tonotopic gradient. In the high and middle CF neurons, the EPSC was large and generated in an all-or-none manner; however, in the low CF neurons, EPSC was small and graded (Fig. 6). The terminal structures of ANFs enfolded the high and middle CF neurons, but these enfolding terminals were not found in the low CF neurons (Fig. 8). Because the NM is required for preservation of temporal information and its synaptic response apparently varies systematically along the tonotopic axis, it may be that temporal coding is regulated in a frequency-dependent manner. The kinetics and amplitude of the mEPSC and EPSC of middle or high CF neurons were almost the same as those reported by Brenowitz and Trussell (2001).

The functional gradient of NM neurons that we report here appears to reflect the mature form because of the following three reasons. First, in the cochlear ganglion of embryonic day 19 (E19), the tuning curve was similar to the one of posthatched chickens, except for the limitation in high-frequency sensitivity (Jones and Jones, 1995). Second, the development of the cochlea is reported to begin from the base or the midbasal region toward the apex, and at a given location in the NM, the CF of neurons increased during development. Large developmental changes were observed in all frequency sectors of the NM between E17 and $\mathrm{P} 0$, but the average $\mathrm{CF}$ was shown to be approaching adult values soon after hatching (Lippe and Rubel, 1985; Lippe, 1987). Third, we consistently found in chickens that a significant gradient is present in the $\mathrm{NM}$ in the expression of Kv1.1, in both mRNA (P3-P15) and antibody (P3-P11).

\section{Expression of DTX-sensitive currents}

Channels of Kv1.1, Kv1.2, and Kv1.6 are blocked by DTX (Hopkins et al., 1994; Harvey, 2001). Among these channels, Kv1.1
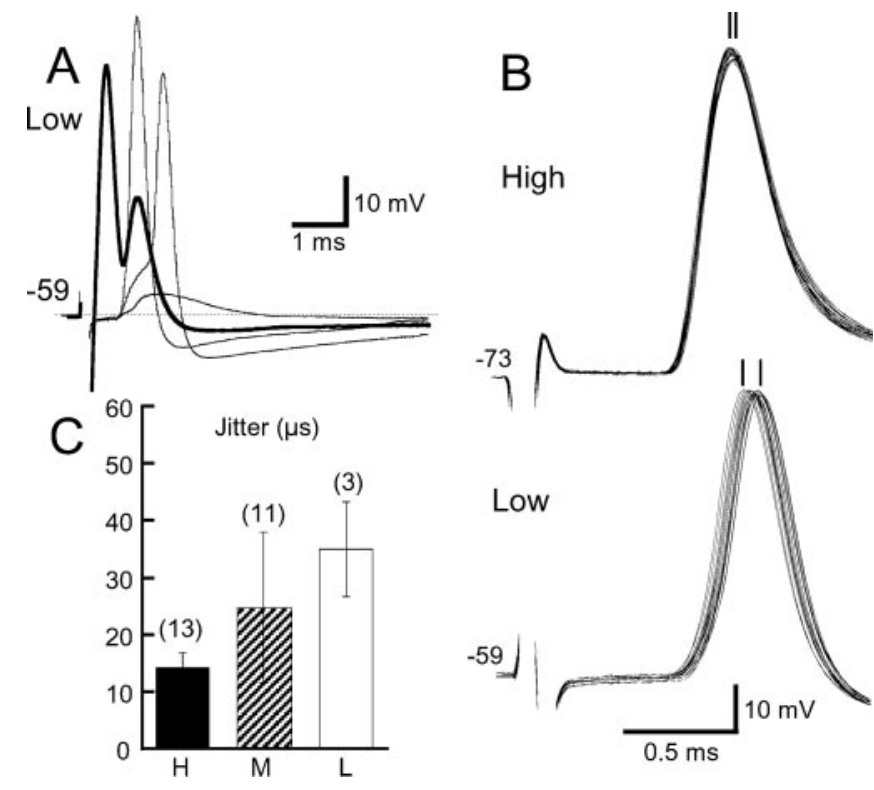

Figure 7. Orthodromic spikes and temporal jitter after ANF stimulation. A, Voltage responses of a low CF neuron. The spike was elicited by the stimulation of ANF. The stimulus intensity was increased in four steps. At the highest stimulus intensity, an antidromic spike was generated, which had no delay from the stimulus artifact (thick line). Six of 10 low (F neurons showed EPSP without generating spikes. $B$, Superimposed traces show temporal jitter of spikes (20 traces for the high CF, 16 traces for the low (F neuron). The bars indicate the distribution of peak time of the spike when the same stimulus was applied every $10 \mathrm{sec}$. The stimulus applied to the low CF ANFs was the maximum intensity but did not generate the antidromic spike. $C$, Jitters of spike generation were measured from a series of 20-60 spikes recorded in a single neuron. The difference between the high and low CF neurons was not statistically significant. $H$, High CF; M, middle CF; L, low CF.

expression showed gradients systematically along the tonotopic axis (Figs. 2, 3). Kv1.2 did not show tonotopic differences, and the expression of Kv1.6 was very weak or nonexistent (Fig. 2). Thus, different membrane excitability among NM neurons is probably created by the graded expression of Kv1.1. In LSO principal neuron, Kv1 channels underlie the gradient of firing properties of single spiking neurons (Barnes-Davies et al., 2004). It is likely that the gradient of Kv1.1 may reflect some graded dominance of heteromeric composition of Kv1.1 and Kv1.2 along the tonotopic axis. In medial nucleus of the trapezoid body principal neurons, the heteromeric channels of Kv1.1/Kv1.2 subunits, but not Kv1.1/ Kv1.6, seems critical in generating the phenotype of the single action potential response of the neuron (Dodson et al., 2002). In the NM, 

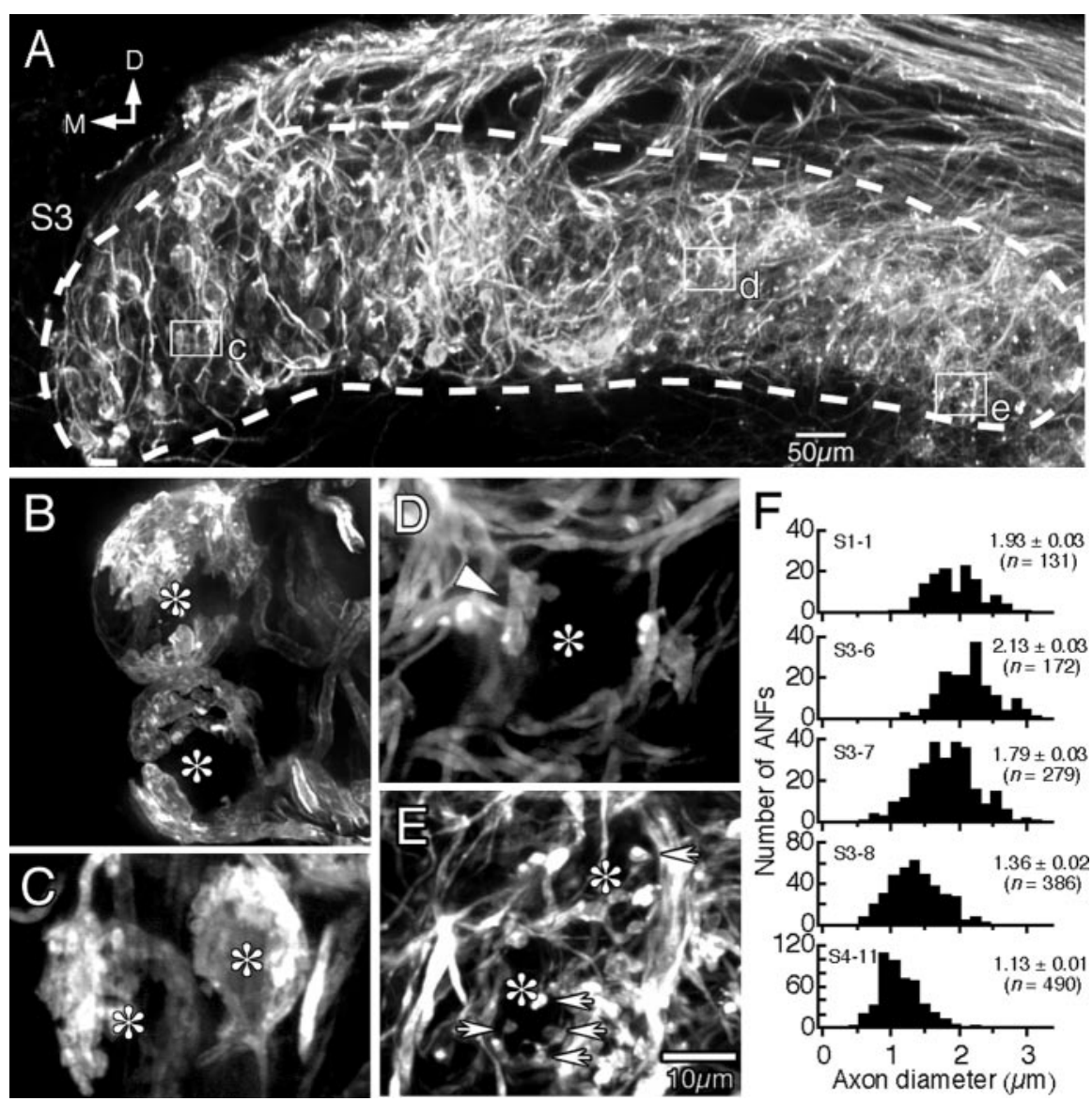

Figure 8. Difference of terminal structures of ANFs along the CF region. A, Patterns of projection of Dil-labeled ANFs in S3 (see Fig. 1). Dil was placed in the fixed preparation in the cochlea. The dashed line indicates the outline of the nucleus. ANFs projected to NM neurons from the dorsolateral region of the slice are shown. Boxes $c-e$ are shown at higher magnification in $C-E$. $B$, End-bulb of Held in high (F region (region 2 of S1). Neurons were innervated by at least two nerve endings, and the terminal was large and enfolding the neuronal soma (asterisks). Calibration bar (in $E$ ) applies to $B-E$. C, Middle (F region. Large synaptic terminals were formed on neuronal soma (asterisks). D, Intermediate region between middle CF and low CF. A cluster of nerve terminals was formed on neuronal soma (arrowhead); however, terminal structures were smaller than those found in the middle or high CF region. E, Low CF region. Large enfolding terminals were not found, but many bouton-shaped terminals (arrows) were observed on cell soma. F, Gradient of axonal diameter was measured along a line crossing the center of regions 1,6, 7, 8, and 11 from four chickens, and the mean \pm SE ( $n=$ number of axons) was indicated in each panel.

$\mathrm{K}^{+}$channels of other phenotypes may also contribute to the differential membrane property, such as the tonotopic differential expression of Kv3.1 (Parameshwaran et al., 2001).

DTX-sensitive current has an important role in determining the membrane time constant and the resting potential of the NM neuron. By the dominant expression of a DTX-sensitive current, high CF neurons have a smaller time constant, a more negative resting potential, and a higher threshold current and threshold potential (Fig. 5A). The smaller time constant is likely to enable the neuron to reset the membrane potential quickly and to endow the neuron with the ability to respond accurately to highfrequency stimuli (Reyes et al., 1994; Zhang and Trussell, 1994; Koyano et al., 1996). In contrast, the low CF neurons have less DTX-sensitive current and longer membrane time constants (Fig. 5Ac). Therefore, the low CF neurons may have different roles in temporal coding than the high CF neurons. These features may allow the low CF neurons to phase-lock more stably to a low-frequency input.
Gradients of synaptic transmission and terminal morphology

The large synaptic currents recorded in the high CF and middle CF neurons would rapidly depolarize the postsynaptic membrane and reduce the temporal jitter in the spike generation. In these neurons, the spike height was significantly larger when triggered trans-synaptically than when generated by current injections (Figs. 5Ae, $7 B)$. This indicates that the large EPSC provides a substantial amount of inward current to charge the membrane and consequently, the action potentials are generated with a minimum time fluctuation. This feature should increase the temporal precision of the high and middle CF NM neurons.

The average amplitude of the sEPSC, which is probably generated by the activation of one ANF, was $\sim 13$ times larger in the high CF neuron than the low CF neurons (12.8 vs $1.0 \mathrm{nA}$ ) (Fig. $6 C d$ ). In the low CF neurons, the size of EPSC was increased gradually with the increase in stimulus intensity (Fig. $6 A c, B c$ ), and the sEPSCs recorded at $-30 \mathrm{mV}$ were $0.05-3$ $\mathrm{nA}$. The size of mEPSC was $0.06 \mathrm{nA}$, indicating that the sEPSC may correspond with a single quantum; in this calculation, the mEPSC was recorded at $-60 \mathrm{mV}$, and the size was converted to the one at -30 $\mathrm{mV}$, assuming the reversal potential as 0 $\mathrm{mV}$. In the high CF and the middle CF regions, neurons are enfolded by endbulbs (Fig. $8 B, C$ ). In the low $\mathrm{CF}$ region, however, large synaptic endings were not observed (Fig. 8E). Therefore, the synaptic currents in the low CF neurons are most likely generated through activities of a number of small endings. In the barn owl, low CF ANF also formed terminal boutons (Köppl, 1994; Köppl and Carr, 1997).

A unique pattern of innervation of the low CF neurons may be expected from the relationship between the basilar papilla and the NM. The low CF region (lower than $500 \mathrm{~Hz}$ ) occupies $\sim 40-$ $50 \%$ of the basilar papilla from the apex (Ryals and Rubel, 1982). However, the percentage of NM area to which ANFs of low CF may project is only 25\% (Lippe and Rubel, 1985). Moreover, the basilar papilla is wider toward the apex (the low frequency region), and the density of hair cells in the apex ( 25 cells per $100 \mu \mathrm{m}$ length of basilar papilla) is approximately three times higher than that in the base (5-10 cells per $100 \mu \mathrm{m}$ length of basilar papilla) (Ryals and Rubel, 1982; Tilney and Saunders, 1983). Numerically, the number of ANFs innervating one low CF neuron could be approximately five times greater than that of the high $\mathrm{CF}$ neurons.

\section{Phase locking in the low CF neurons}

Vector strengths, or synchrony of discharge to tones, are greater at lower CFs (Goldberg and Brown, 1969). Vector strength values of 0.75 at $0.4 \mathrm{kHz}$ and 0.55 at $1.6 \mathrm{kHz}$ are reported in the chicken 
(Salvi et al., 1992). However, in the low CF ANFs, the temporal jitter of firing could still be significantly larger than that in the high CF fibers (Hill et al., 1989). Because a stimulus cycle at low frequency has a longer period than one at higher CF, the high vector strength cited above still permits a temporal jitter approximately three times larger in the low CF ANFs.

However, because of the specialization of synaptic transmission in the low CF region, the temporal coding could be improved in these neurons. The low CF neurons are thought to be innervated by multiple ANFs having relatively small synaptic terminals (Fig. 8), and the EPSPs that they receive are of subthreshold intensities (Fig. 6). Thus, coincidental EPSC inputs are required to fire the neuron. This process of input integration and coincidence detection may improve the low CF neurons to fire more at the synchronized timing than do ANFs. At the low CF neurons in anteroventral cochlea nucleus of cat, ANFs with different CFs were found converged, which is proposed to be effective in improving the tuning property of the neuron and in enhancing the signal-to-noise ratio (Carney, 1990). The synchronization of firing was actually steeper than the input ANFs in the spherical busy cells of the cat, where convergence of several low CF ANFs was made (Joris et al., 1994). In contrast, in the barn owl at CF of $0.5-10 \mathrm{kHz}$, improvements of the vector strength was not observed in the $\mathrm{NM}$, and the vector strength was the same as or smaller than that of ANFs of corresponding CF (Köppl, 1997). The low CF NM neurons that we discuss here probably have a CF lower than $0.5 \mathrm{kHz}$, and this region of CF may not have been fully investigated in the barn owl. The vector strength of NM firing was reported as being $\sim 0.8$ at $0.4 \mathrm{kHz}$ CF region in the chicken (Warchol and Dallos, 1990), and this is the same level of synchronization as that found in the ANFs at these CFs (Salvi et al., 1992). Both in the chicken and in the barn owl, additional examinations will be necessary regarding the temporal jitter and the possible improvement of temporal coding of neurons in the low CF region of NM by in vivo experiments.

\section{References}

Barnes-Davies M, Barker MC, Osmani F, Forsythe ID (2004) Kv1 currents mediate a gradient of principal neuron excitability across the tonotopic axis in the rat lateral superior olive. Eur J Neurosci 19:325-333.

Brainard MS, Knudsen EI, Esterly SD (1992) Neural derivation of sound source location: resolution of spatial ambiguities in binaural cues. J Acoust Soc Am 91:1015-1027.

Brenowitz S, Trussell LO (2001) Maturation of synaptic transmission at end-bulb synaptic of the cochlear nucleus. J Neurosci 21:9487-9498.

Carney LH (1990) Sensitivities of cells in anteroventral cochlear nucleus of cat to spatiotemporal discharge patterns across primary afferents. J Neurophysiol 64:437-456.

Carr CE, Boudreau RE (1991) Central projection of auditory nerve fibers in the barn owl. J Comp Neurol 314:306-318.

Carr CE, Konishi M (1990) A circuit for detection of interaural time differences in the brain stem of the barn owl. J Neurosci 10:3227-3246.

Dodson PD, Barker MC, Forsythe D (2002) Two heteromeric Kv1 potassium channels differentially regulate action potential firing. J Neurosci 22:6953-6961.

Fukui I, Ohmori H (2003) Developmental changes in membrane excitability and morphology of neurons in the nucleus angularis of the chicken. J Physiol (Lond) 548:219-232.

Goldberg JM, Brown PB (1969) Response of binaural neurons of dog superior olivary complex to dichotic tonal stimuli: some physiological mechanisms of sound localization. J Neurophysiol 32:613-636.

Hackett JT, Jackson H, Rubel EW (1982) Synaptic excitation of the second and third order auditory neurons in the avian brain stem. Neuroscience 7:1455-1469.

Harvey AL (2001) Twenty years of dendrotoxins. Toxicon 39:15-26.
Hill KG, Stange G, Mo JW (1989) Temporal synchronization in the primary auditory response in the pigeon. Hearing Res 39:63-74.

Hopkins WF, Allen ML, Houamed KM, Tempel BL (1994) Properties of voltage-gated $\mathrm{K}^{+}$currents expressed in Xenopus oocytes by mKv1.1, $\mathrm{mKv} 1.2$ and their heteromultimers as revealed by mutagenesis of the dendrotoxin-binding site in mKv1.1. Pflügers Arch 428:382-390.

Jhaveri S, Morest DK (1982a) Neuronal architecture in nucleus magnocellularis of the chicken auditory system with observations on nucleus laminaris: a light and electron microscope study. Neuroscience 7:809-836.

Jhaveri S, Morest DK (1982b) Sequential alterations of neuronal architecture in nucleus magnocellularis of the developing chicken: a Golgi study. Neuroscience 7:837-853.

Jhaveri S, Morest DK (1982c) Sequential alterations of neuronal architecture in nucleus magnocellularis of the developing chicken: an electron microscope study. Neuroscience 7:855-870.

Jones SM, Jones TA (1995) The tonotopic map in the embryonic chicken cochlear. Hearing Res 82:149-157.

Joris PX, Carney LH, Smith PH, Yin TCT (1994) Enhancement of neural synchronization in the anteroventral cochlear nucleus. I. Responses to tones at the characteristic frequency. J Neurosci 5:275-283.

Knudsen EI, Konishi M (1978) A neural map of auditory space in the owl. Science 200:795-797.

Köppl C (1994) Auditory nerve terminals in the cochlear nucleus magnocellularis: differences between low and high frequencies. J Comp Neurol 339:438-446.

Köppl C (1997) Phase locking to high frequencies in the auditory nerve and cochlear nucleus magnocellularis of the barn owl, Tyto alba. J Neurosci 1997:3312-3321.

Köppl C, Carr CE (1997) Low-frequency pathway in the barn owl's auditory brainstem. J Comp Neurol 378:265-282.

Koyano K, Funabiki K, Ohmori H (1996) Voltage-gated ionic currents and their roles in timing coding in auditory neurons of the nucleus magnocellularis of the chick. Neurosci Res 26:29-45.

Lippe W (1987) Shift of tonotopic organization in brain stem auditory nuclei of the chicken during late embryonic development. Hearing Res 25:205-208.

Lippe W, Rubel EW (1985) Ontogeny of tonotopic organization of brain stem auditory nuclei in the chicken: implications for development of the place principle. J Comp Neurol 237:273-289.

Lu Y, Monsivais P, Tempel BL, Rubel EW (2004) Activity-dependent regulation of the potassium channel subunits Kv1.1 and Kv3.1. J Comp Neurol 23:93-106.

Overholt EM, Rubel EW, Hyson RL (1992) A circuit for coding interaural time differences in the chick brainstem. J Neurosci 12:1698-1708.

Pantelias AA, Monsivais P, Rubel EW (2001) Tonotopic map of potassium currents in chick auditory hair cells using an intact basilar papilla. Hear Res 156:81-94.

Parameshwaran S, Carr CE, Perney TM (2001) Expression of the Kv3.1 potassium channel in the avian auditory brainstem. J Neurosci 21:485-494.

Parks TN, Rubel EW (1978) Organization and development of the brain stem auditory nuclei of the chicken: primary afferent projections. J Comp Neurol 180:439-448.

Ramanathan K, Michael TH, Jiang GJ, Hiel H, Fuchs PA (1999) A molecular mechanism for electrical tuning of cochlear hair cells. Science 283:215-217.

Ramanathan K, Michael TH, Fuchs PA (2000) $\beta$ subunits modulate alternatively spliced, large conductance, calcium-activated potassium channels of avian hair cells. J Neurosci 20:1675-1684.

Rathouz M, Trussell L (1998) Characterization of outward currents in neurons of the avian nucleus magnocellularis. J Neurophysiol 80:2824-2835.

Reyes AD, Rubel EW, Spain WJ (1994) Membrane properties underlying the firing of neurons in the avian cochlear nucleus. J Neurosci 14:5352-5364.

Rubel EW, Parks TN (1975) Organization and development of brain stem auditory nuclei of the chicken: tonotopic organization of N. magnocellularis and N. laminaris. J Comp Neurol 164:411-434.

Ryals BM, Rubel EW (1982) Patterns of hair cell loss in chick basilar papilla after intense auditory stimulation. Acta Otolaryngol 93:205-210.

Salvi RJ, Saunders SS, Powers NL, Boettcher FA (1992) Discharge patterns of cochlear ganglion neurons in the chicken. J Comp Physiol [A] 170:227-241. 
Sullivan WE, Konishi M (1984) Segregation of stimulus phase and intensity coding in the cochlear nucleus of the barn owl. J Neurosci 4:1787-1799.

Takahashi T, Moiseff A, Konishi M (1984) Time and intensity cues are processed independently in the auditory system of the owl. J Neurosci 4:1781-1786.

Takahashi TT, Konishi M (1988a) Projections of the cochlear nuclei and nucleus laminaris to the inferior colliculus of the barn owl. J Comp Neurol 274:190-211.

Takahashi TT, Konishi M (1988b) Projections of nucleus angularis and nucleus laminaris to the lateral lemniscal nuclear complex of the barn owl. J Comp Neurol 274:212-238.

Tilney LG, Saunders JC (1983) Actin filaments, stereocilia, and hair cell of the bird cochlea. I. Length, number, width, and distribution of stereocilia of each hair cell are related to the position of the hair cell on the cochlea. J Cell Biol 96:807-821.

Warchol ME, Dallos P (1990) Neural coding in the chick cochlear nucleus. J Comp Physiol A 166:721-734.

Whitehead MC, Morest DK (1981) Dual populations of efferent and afferent cochlear axons in the chicken. Neuroscience 6:2351-2365.

Wu YC, Art JJ, Goodman MB, Fettiplace R (1995) A kinetic description of the calcium-activated potassium channel and its application to electrical tuning of hair cells. Prog Biophys Mol Biol 63:131-158.

Young SR, Rubel EW (1983) Frequency-specific projections of individual neurons in chick brainstem auditory nuclei. J Neurosci 3:1373-1378.

Zhang S, Trussell LO (1994) A characterization of excitatory postsynaptic potentials in the avian nucleus magnocellularis. J Neurophysiol 72:705-718. 